\title{
Influence of Oil Viscosity on Alkaline Flooding for Enhanced Heavy Oil Recovery
}

\author{
Yong Du, ${ }^{1,2}$ Guicai Zhang, ${ }^{1}$ Jijiang Ge, ${ }^{1}$ Guanghui Li, ${ }^{1}$ and Anzhou Feng ${ }^{3}$ \\ ${ }^{1}$ College of Petroleum Engineering, China University of Petroleum, Qingdao 266555, China \\ ${ }^{2}$ Zhuangxi Oil Production Plant, Shengli Oilfield, Sinopec, Dongying 257237, China \\ ${ }^{3}$ Xinchun Production Plant, Shengli Oilfield, Sinopec, China \\ Correspondence should be addressed to Jijiang Ge; gejijiang@163.com
}

Received 21 March 2013; Accepted 25 June 2013

Academic Editor: Ibnelwaleed Ali Hussien

Copyright (C) 2013 Yong Du et al. This is an open access article distributed under the Creative Commons Attribution License, which permits unrestricted use, distribution, and reproduction in any medium, provided the original work is properly cited.

\begin{abstract}
Oil viscosity was studied as an important factor for alkaline flooding based on the mechanism of "water drops" flow. Alkaline flooding for two oil samples with different viscosities but similar acid numbers was compared. Besides, series flooding tests for the same oil sample were conducted at different temperatures and permeabilities. The results of flooding tests indicated that a high tertiary oil recovery could be achieved only in the low-permeability (approximately $500 \mathrm{mD}$ ) sandpacks for the low-viscosity heavy oil (Zhuangxi, $390 \mathrm{mPa} \cdot \mathrm{s}$ ); however, the high-viscosity heavy oil (Chenzhuang, $3450 \mathrm{mPa} \cdot \mathrm{s}$ ) performed well in both the low- and medium-permeability (approximately $1000 \mathrm{mD}$ ) sandpacks. In addition, the results of flooding tests for the same oil at different temperatures also indicated that the oil viscosity put a similar effect on alkaline flooding. Therefore, oil with a high-viscosity is favorable for alkaline flooding. The microscopic flooding test indicated that the water drops produced during alkaline flooding for oils with different viscosities differed significantly in their sizes, which might influence the flow behaviors and therefore the sweep efficiencies of alkaline fluids. This study provides an evidence for the feasibility of the development of high-viscosity heavy oil using alkaline flooding.
\end{abstract}

\section{Introduction}

Thermal methods are the primary ways to develop heavy oil reservoirs. However, severe heat losses reduce the effectiveness of thermal processes in deep or thin heavy oil reservoirs and increase the production cost. Inexpensive alkaline reagents can react with the organic acids in heavy oil and form massive amounts of surfactant in situ at the oil/water interface, by which the interface tension (IFT) can be reduced greatly [1-5]. In recent years, a new mechanism proposed by Ding et al. [6] has attracted the attention of researchers. He described the interfacial reaction between the oil phase and the alkaline solution in detail and proposed two stages related to the reaction during the alkaline flooding process. The first stage was the occurrence of water columns that resulted from the penetration of the alkaline solution into the crude oil. The second stage was the division of these water columns into small discontinuous water droplets due to the nonuniform enrichment of surfactants at the oil/water interface. The viscous fingering effect was significantly reduced by the presence of water drops inside the oil phase. In contrast, the water in oil (W/O) emulsion was simply a byproduct of alkaline liquid penetration rather than the basic mechanism of enhanced oil recovery (EOR) during alkaline flooding. They also observed differences of water breakthrough and alkaline breakthrough. In water flooding, after water breaks through, several connected water channels are created diagonally and little oil can be recovered by continued water flooding. Consequently, most of the oil is bypassed, due to the viscous fingering caused by the adverse mobility ratio between the oil and the water. In alkaline flooding, after alkaline breaks through, it can be seen that relatively uniform degree oil saturation is distributed over the entire model. Oil is subsequently displaced in the form of the "water drop" with little viscous fingering. Therefore, it is the "water drop" mechanism that reduces the mobility of water phase and diverts the injected alkaline solution to the unswept region of micromodel to improve the sweep efficiency. 
The mechanism of "water drops" flow allowed the successful interpretation to some phenomena in alkaline flooding.

Many factors influence the performance of alkaline flooding. Arhuoma et al. [7] investigated the influence of alkaline concentration on the alkaline flooding for Alberta heavy oil through sandpack flooding tests using $\mathrm{NaOH}$ as the alkaline reagent. Their results indicated that the recovery initially increased with the increase of alkaline concentration; afterwards, the variation became very slight or even decreased, which suggests that an optimum concentration exists for enhancing the oil recovery. Almalik et al. [8] have studied the influence of the alkaline type and the injection mode on oil recovery. They observed that $\mathrm{NaOH}$ performed better than $\mathrm{Na}_{3} \mathrm{PO}_{4} \cdot 12 \mathrm{H}_{2} \mathrm{O}$ and $\mathrm{KOH}$ under identical conditions, and the continuous alkaline flooding yielded a higher recovery than when slugs were used. Previous research has been primarily focused on these dynamic injection conditions. However, a few static reservoir conditions have been also studied in some reports. Chiwetelu et al. [9] and Trujillo [10] have investigated the influence of reservoir temperature on alkaline flooding, the results showed that about $12 \%$ more oil was recovered at $65^{\circ} \mathrm{C}$ than at $25^{\circ} \mathrm{C}$, and the IFT values were significantly greater at higher temperatures which was considered as the main reason for the change regulation.

The static conditions of heavy oil reservoirs are complicated and different with each other, which can also influence the effectiveness of alkaline flooding significantly. Among these static conditions, oil viscosity may exhibit the largest variation range in heavy oil reservoirs. However, the previous study about this aspect is insufficient to satisfy the requirement to design a good EOR plan. Therefore, the influence of oil viscosity on alkaline flooding in heavy oil reservoirs is investigated here by sandpack flooding experiments.

\section{Experimental}

2.1. Fluids and Chemicals. Oil samples were collected from the heavy oil reservoirs of Zhuangxi, Chenzhuang, Xia-8 and Binnan in Shengli Oilfield; their viscosities were measured by a rotary viscometer, and the viscosity-temperature properties are shown in Figure 1. The acid-number of these four oil samples were measured by potentiometric titration method, and the results are listed in Table 1 . All the aqueous phase was brine that contained $0.5 \mathrm{wt} \% \mathrm{NaCl}$. Chemicals used in this study, such as $\mathrm{NaOH}$ and $\mathrm{NaCl}$, were all analytical-grade reagents supplied by Sinopharm.

2.2. IFT Measurements. The dynamic IFT values between heavy oil and alkaline solutions were measured at $50^{\circ} \mathrm{C}$ using an American Texas-500 spinning drop tensiometer according to the following:

$$
\sigma=1.2336\left(\rho_{w}-\rho_{o}\right) \omega^{2}\left(\frac{D}{n}\right)^{3}, \quad \frac{L}{D} \geq 4,
$$

where $\sigma$ is the interfacial tension $(\mathrm{mN} / \mathrm{m}), \rho_{w}$ is the density of the water phase $\left(\mathrm{g} / \mathrm{cm}^{3}\right), \rho_{o}$ is the density of the oil phase $\left(\mathrm{g} / \mathrm{cm}^{3}\right), \omega$ is the rotational velocity $(\mathrm{rpm}), D$ is the measured

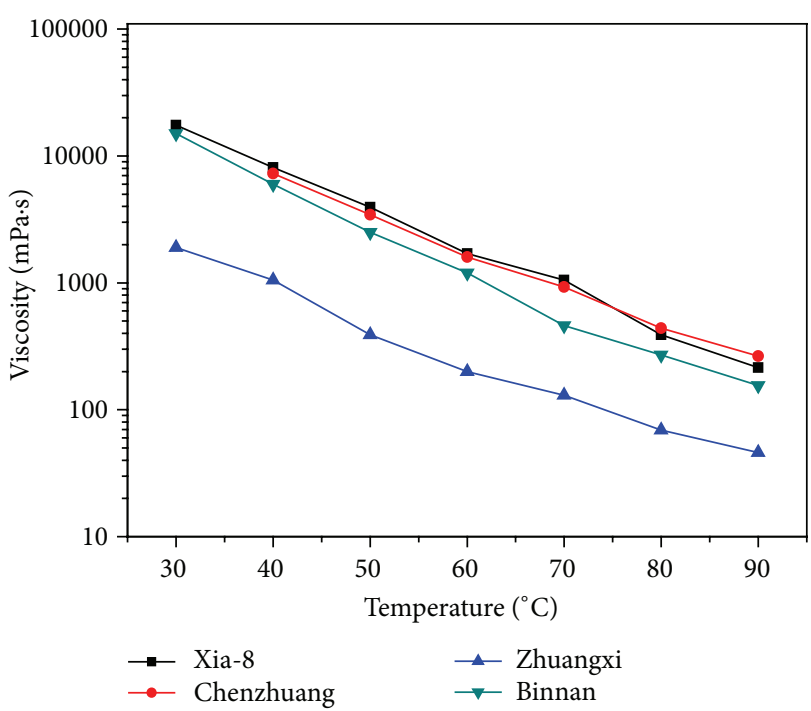

FIGURE 1: Viscosity-temperature curves of four types of heavy oil.

drop width (mm), $L$ is the length of the oil drop ( $\mathrm{mm})$, and $n$ is the refractive index of the water phase.

2.3. Microscopic Flooding Tests. The glass-etched micromodel was used to investigate the displacement mechanisms of alkaline flooding. The micromodel was made by the two same glass plates which were impacted tightly, and the pore throats were etched on the interface by special corrosive substances. The procedure of the microscopic flooding test was described as follows: the micromodel was first saturated with brine after being vacuumed, and it was subsequently displaced by heavy oil until no more brine was produced. The alkaline solution was then injected at a constant flow rate of $0.003 \mathrm{~mL} / \mathrm{min}$. The flooding tests can be visualized using a video recorder and camera apparatus.

2.4. Sandpack Flooding Tests. The sandpacks used in this study were $30 \mathrm{~cm}$ in length and $2.45 \mathrm{~cm}$ in diameter. They were wet-packed as follows: first, fresh quartz sand with 100200 and $80-100$ mesh sizes was blended at a weight ratio of $3: 1$. The sandpack was positioned vertically, and the sand was then added into the sandpack filled with brine water in several increments. In each step, the sand in the sandpack was shaken slightly after being added. The water surface was kept above the sand surface to avoid the intrusion of air.

The sandpack displacement was conducted at $50^{\circ} \mathrm{C}$ using the following procedure: first, the sandpack was saturated with brine solution, and then the permeability was measured and the porosity was calculated. Afterward, the sandpack was subsequently saturated with the heavy oil until no more water was produced (the water cut was less than approximately 1 vol\%). After the oil injection, water flooding was conducted until the oil cut was less than 1 vol\%, and then a chemical slug of 0.3 pore volume (PV) was injected. The injection of the chemical slug was followed by an extended period of water flooding until the oil production became negligible (oil cut 
TABLE 1: Basic properties of four types of heavy oil.

\begin{tabular}{lccc}
\hline Heavy oil & Density at $50^{\circ} \mathrm{C}\left(\mathrm{g} / \mathrm{cm}^{3}\right)$ & Viscosity at $50^{\circ} \mathrm{C}(\mathrm{mPa} \cdot \mathrm{s})$ & Acid number $(\mathrm{mg} \mathrm{KOH}$ per g sample $)$ \\
\hline Zhuangxi & 0.9302 & 390 & 1.85 \\
Chenzhuang & 0.9778 & 3450 & 2.02 \\
Binnan & 0.9632 & 2500 & 3.85 \\
Xia-8 & 0.9712 & 3950 & 4.66 \\
\hline
\end{tabular}

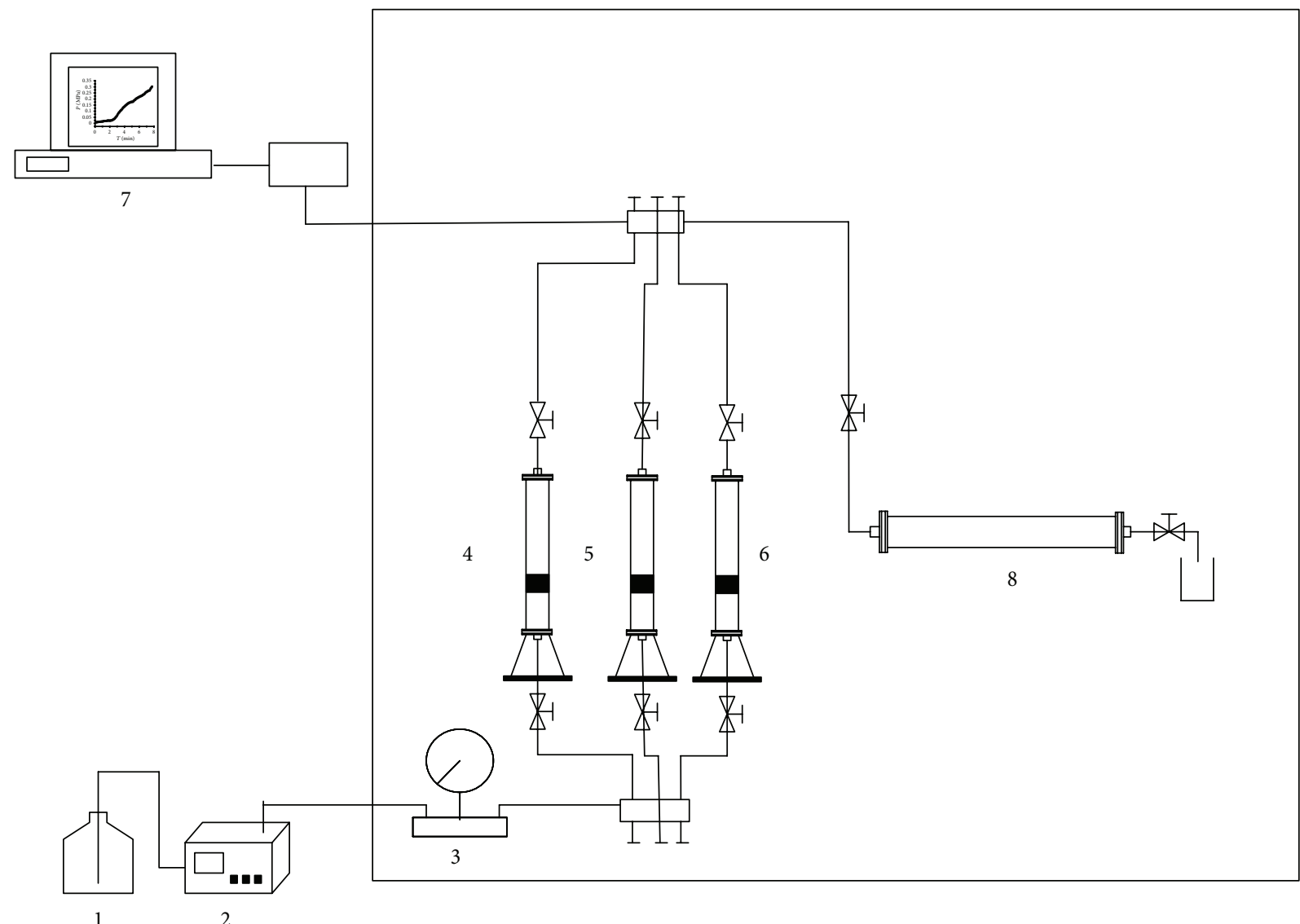

FIGURE 2: The equipment for sandpack flooding. 1, distilled water; 2, pump; 3, pressure meter; 4, brine water container; 5 , crude oil container; 6, alkaline solution container; 7, pressure collection system; 8, Sandpack model.

$<1$ vol\%). The injection rate of the brine solution and the chemical slug was set at $0.5 \mathrm{~mL} / \mathrm{min}$.

The equipment for the sandpack flooding is shown in Figure 2.

\section{Results and Discussion}

3.1. Performance of Alkaline Flooding for Oils with Different Viscosities. To investigate the influence of oil viscosity on the performance of alkaline flooding, alkaline flooding for two oil samples with different viscosities, and similar acid numbers were compared. Then, series flooding tests for the same oil sample were conducted at different temperatures.

Zhuangxi and Chenzhuang heavy oil were selected for their similar acid numbers and different viscosities, as shown in Figure 1 and Table 1. 18 alkaline flooding tests (Runs
$1 \sim 18$ ) were conducted in sandpacks with three levels of permeability: low-permeability (approximately $500 \mathrm{mD}$ ), medium-permeability (approximately $1000 \mathrm{mD}$ ), and highpermeability (approximately $2000 \mathrm{mD}$ ). Three alkaline concentrations were investigated at each permeability level. The parameters of the sandpacks, the chemical formulas, and the flood results are summarized in Table 2.

The alkaline flooding performances of these two oil samples were significantly different, as shown in Figures 3 and 4 . The correspondingly dynamic recovery with the production is shown in Figure 5. For the Zhuangxi heavy oil with a relative low-viscosity, the incremental oil recovery was greater than $20 \%$ when the sandpack permeability was approximately $500 \mathrm{mD}$; however, it declined significantly as the permeability increased, and the tertiary oil recovery was only $5 \sim 10 \%$ in the high-permeability sandpacks. For the Chenzhuang heavy oil, which exhibits a higher 
TABLE 2: Summary of sandpack flooding tests for different heavy oils.

\begin{tabular}{|c|c|c|c|c|c|c|c|c|}
\hline \multirow{2}{*}{ Run no. } & \multirow{2}{*}{ Heavy oil } & \multirow{2}{*}{$\begin{array}{l}\text { Permeability } \\
\quad(\mathrm{mD})\end{array}$} & \multirow{2}{*}{$\begin{array}{c}\text { Initial oil } \\
\text { saturation (\%) }\end{array}$} & \multirow{2}{*}{ Chemical formula } & \multirow{2}{*}{$\begin{array}{l}\text { Equilibrium IFT } \\
\qquad(\mathrm{mN} / \mathrm{m})\end{array}$} & \multicolumn{3}{|c|}{ Recovery (\%) } \\
\hline & & & & & & $\begin{array}{l}\text { Water } \\
\text { flooding }\end{array}$ & $\begin{array}{l}\text { Alkaline } \\
\text { flooding }\end{array}$ & Total \\
\hline 1 & Zhuangxi & 570 & 90.0 & $0.25 \% \mathrm{NaOH}+0.5 \% \mathrm{NaCl}$ & 0.600 & 29.0 & 22.9 & 51.9 \\
\hline 2 & Zhuangxi & 488 & 82.4 & $0.5 \% \mathrm{NaOH}+0.5 \% \mathrm{NaCl}$ & 0.064 & 36.7 & 26.7 & 63.4 \\
\hline 3 & Zhuangxi & 570 & 84.9 & $1 \% \mathrm{NaOH}+0.5 \% \mathrm{NaCl}$ & 0.200 & 23.1 & 29.7 & 52.8 \\
\hline 4 & Zhuangxi & 1120 & 83.7 & $0.25 \% \mathrm{NaOH}+0.5 \% \mathrm{NaCl}$ & 0.600 & 36.7 & 7.2 & 43.9 \\
\hline 5 & Zhuangxi & 985 & 88.1 & $0.5 \% \mathrm{NaOH}+0.5 \% \mathrm{NaCl}$ & 0.064 & 37.5 & 12.4 & 49.9 \\
\hline 6 & Zhuangxi & 1075 & 84.5 & $1 \% \mathrm{NaOH}+0.5 \% \mathrm{NaCl}$ & 0.200 & 35.5 & 16.5 & 52.0 \\
\hline 7 & Zhuangxi & 1875 & 88.0 & $0.25 \% \mathrm{NaOH}+0.5 \% \mathrm{NaCl}$ & 0.600 & 39.4 & 5.6 & 45.0 \\
\hline 8 & Zhuangxi & 2080 & 87.4 & $0.5 \% \mathrm{NaOH}+0.5 \% \mathrm{NaCl}$ & 0.064 & 39.9 & 9.3 & 49.2 \\
\hline 9 & Zhuangxi & 2125 & 89.5 & $1 \% \mathrm{NaOH}+0.5 \% \mathrm{NaCl}$ & 0.200 & 40.6 & 10.4 & 51.0 \\
\hline 10 & Chenzhuang & 558 & 85.1 & $0.25 \% \mathrm{NaOH}+0.5 \% \mathrm{NaCl}$ & 0.122 & 31.8 & 14.7 & 46.5 \\
\hline 11 & Chenzhuang & 577 & 82.6 & $0.5 \% \mathrm{NaOH}+0.5 \% \mathrm{NaCl}$ & 0.096 & 33.2 & 20.1 & 53.3 \\
\hline 12 & Chenzhuang & 543 & 86.3 & $1 \% \mathrm{NaOH}+0.5 \% \mathrm{NaCl}$ & 0.180 & 35.3 & 21.3 & 56.6 \\
\hline 13 & Chenzhuang & 1025 & 84.4 & $0.25 \% \mathrm{NaOH}+0.5 \% \mathrm{NaCl}$ & 0.122 & 35.8 & 15.3 & 51.1 \\
\hline 14 & Chenzhuang & 1180 & 85.7 & $0.5 \% \mathrm{NaOH}+0.5 \% \mathrm{NaCl}$ & 0.096 & 37.3 & 21.4 & 58.7 \\
\hline 15 & Chenzhuang & 1065 & 84.2 & $1 \% \mathrm{NaOH}+0.5 \% \mathrm{NaCl}$ & 0.180 & 37.8 & 23.9 & 61.7 \\
\hline 16 & Chenzhuang & 2135 & 89.1 & $0.25 \% \mathrm{NaOH}+0.5 \% \mathrm{NaCl}$ & 0.122 & 40.2 & 8.6 & 48.8 \\
\hline 17 & Chenzhuang & 2110 & 86.1 & $0.5 \% \mathrm{NaOH}+0.5 \% \mathrm{NaCl}$ & 0.096 & 39.8 & 12.9 & 52.7 \\
\hline 18 & Chenzhuang & 2240 & 88.5 & $1 \% \mathrm{NaOH}+0.5 \% \mathrm{NaCl}$ & 0.180 & 40.2 & 13.5 & 53.7 \\
\hline
\end{tabular}

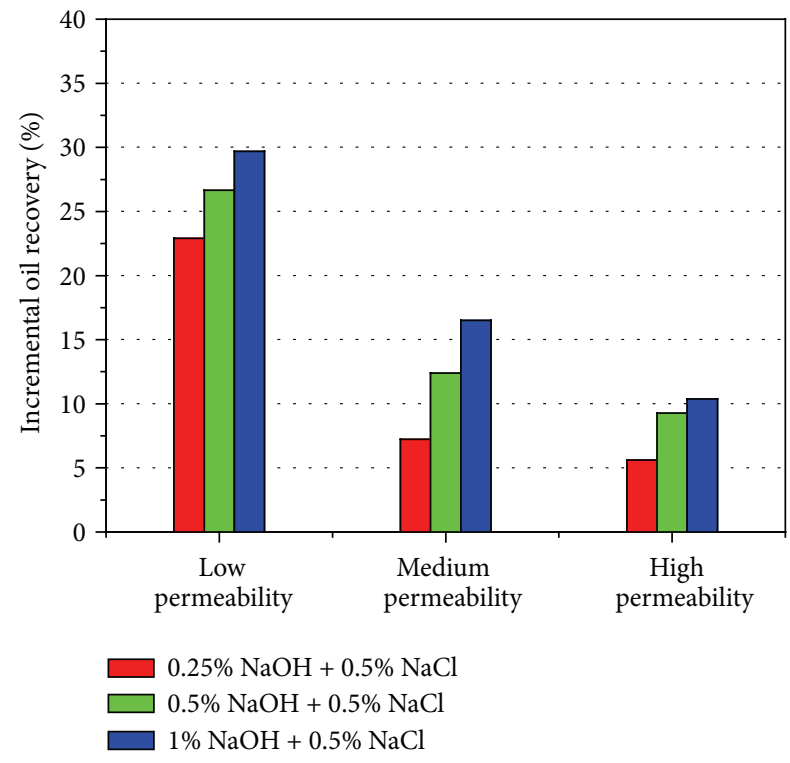

FIGURE 3: Alkaline flooding performance of Zhuangxi heavy oil.

viscosity, the tertiary oil recovery was as high as $20 \%$ at both low- and medium-permeabilities, but it also decreased when the permeability was approximately $2000 \mathrm{mD}$. These results demonstrate that oil with a higher viscosity exhibits a wider range of applicable permeability and that only in the lowpermeability sandpacks can the low-viscosity heavy oil such as Zhuangxi oil achieve a high tertiary oil recovery.

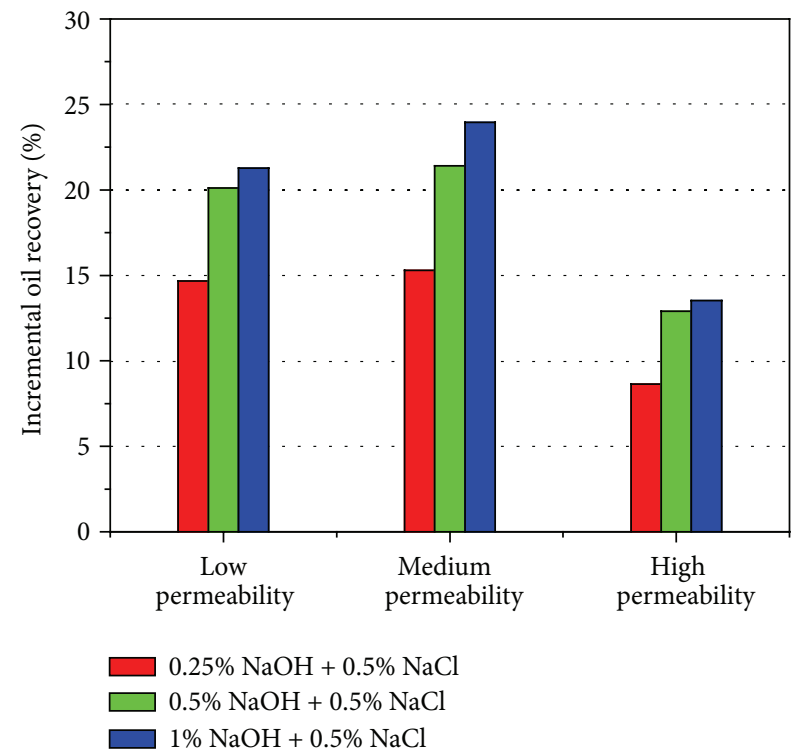

FIGURE 4: Alkaline flooding performance of Chenzhuang heavy oil.

Subsequently, temperature was changed to achieve different oil viscosities for the same oil sample. Xia-8 and Binnan heavy oil were selected for these tests, and their basic properties are also shown in Table 1.

For the Xia- 8 heavy oil, the sandpack flooding tests were conducted at viscosity values of $18,235 \mathrm{mPa} \cdot \mathrm{s}\left(30^{\circ} \mathrm{C}\right)$, $3950 \mathrm{mPa} \cdot \mathrm{s}\left(50^{\circ} \mathrm{C}\right)$, and $1083 \mathrm{mPa} \cdot \mathrm{s}\left(70^{\circ} \mathrm{C}\right)$. Similarly, the tests were performed at viscosity values of $15,030 \mathrm{mPa} \cdot \mathrm{s}\left(30^{\circ} \mathrm{C}\right)$, 


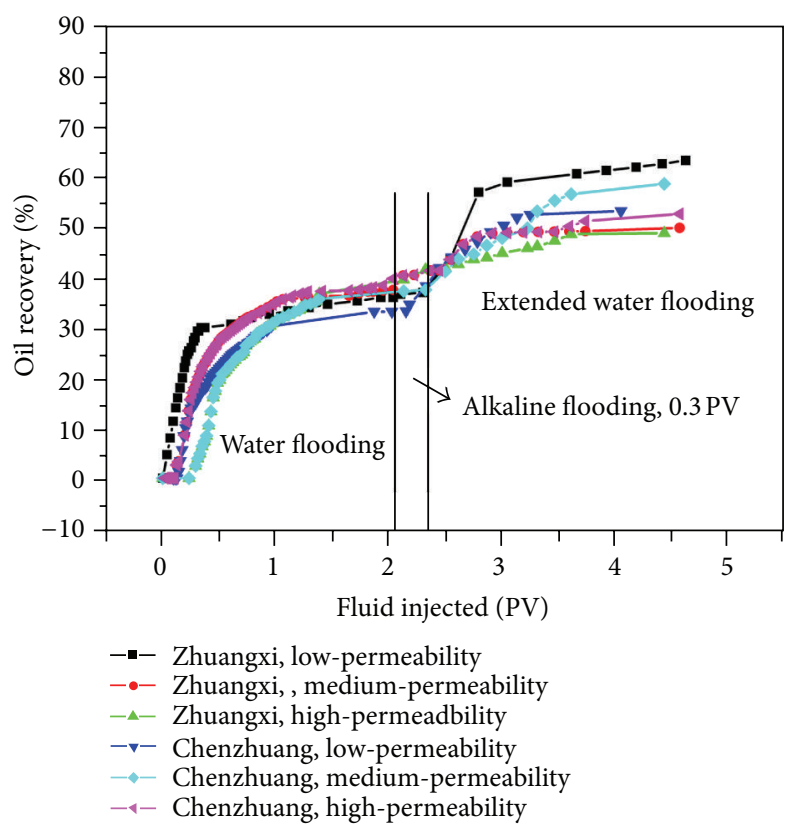

FIGURE 5: Oil recovery curves for different permeability sandpacks (alkaline concentration $=0.5 \mathrm{wt} \%$ ).

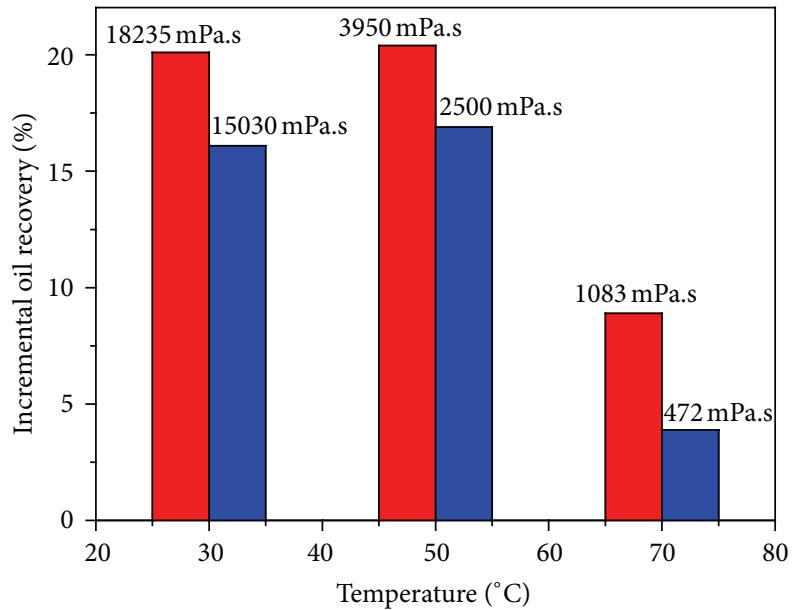

Xia-8

$\square$ Binnan

FIGURE 6: Influence of oil viscosity on the alkaline flooding efficiency.

$2500 \mathrm{mPa} \cdot \mathrm{s}\left(50^{\circ} \mathrm{C}\right)$, and $472 \mathrm{mPa} \cdot \mathrm{s}\left(70^{\circ} \mathrm{C}\right)$ for the Binnan heavy oil. The chemical formula of $0.5 \% \mathrm{NaOH}+0.5 \% \mathrm{NaCl}$ was used for all of the sandpack flooding tests. The test parameters and flood results are summarized in Table 3.

The incremental oil recoveries of the sandpack flooding tests are shown in Figure 6. The results lead to the conclusion that the behaviors of tertiary oil recovery for the two oil samples are similar with the variation of oil viscosity. The incremental oil recovery reached $20 \%$ at $30^{\circ} \mathrm{C}$ and $50^{\circ} \mathrm{C}$ for the oil with high-viscosity, and it declined intensively at $70^{\circ} \mathrm{C}$ for the oil with low-viscosity.

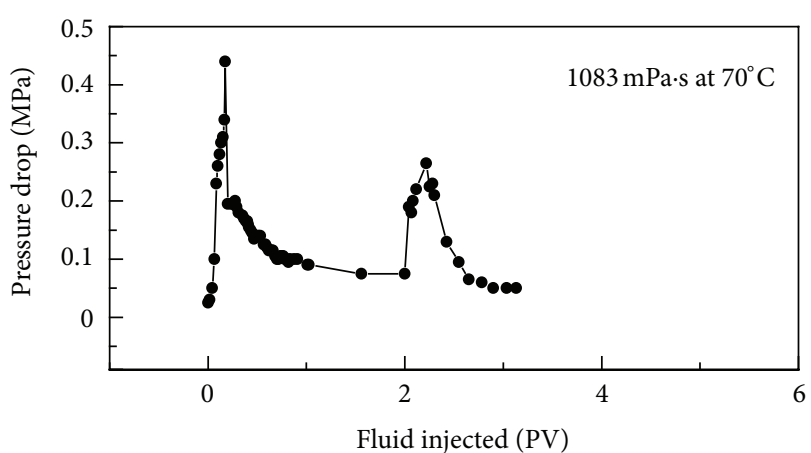

(a)

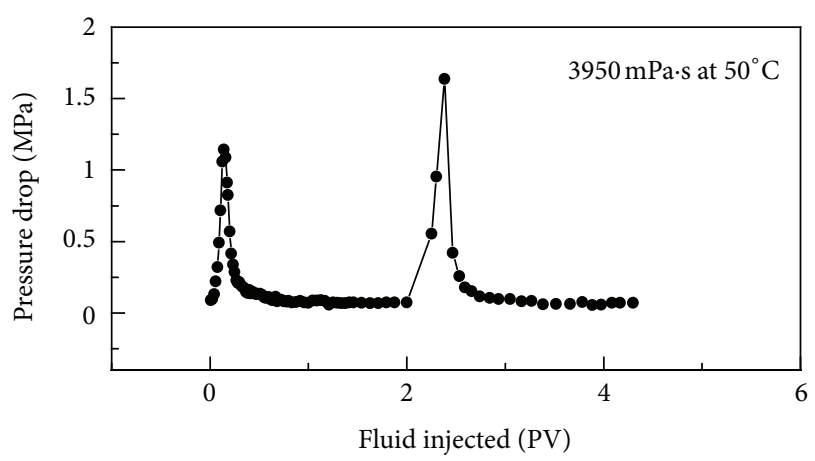

(b)

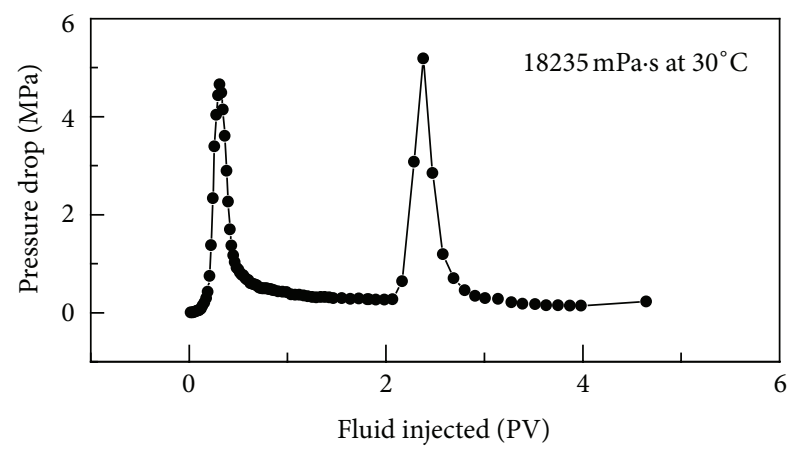

(c)

FIGURE 7: Pressure changes during alkaline flooding for Xia-8 heavy oil with different viscosities.

In Figure 7, the displacement pressure drop is plotted as a function of the injected volume. It shows that the peak pressure drop during alkaline flooding is higher than that during water flooding for the Xia-8 heavy oil, except for the oil at low-viscosity $\left(70^{\circ} \mathrm{C}\right)$. It means that the plugging effect of water drops formed by injected alkaline solution is weakened for the low-viscosity oil sample. This result is consistent with the results of the sandpack flooding tests. Pictures of the effluent in these tests are shown in Figure 8. It can be seen that the interface of the produced fluid is clear, and the upper phase is the water drops inside the oil phase when the oil viscosity is high $\left(30^{\circ} \mathrm{C}\right.$ and $\left.50^{\circ} \mathrm{C}\right)$. However, because the formation of water drops inside the oil phase cannot be implemented easily for the oil with low-viscosity $\left(70^{\circ} \mathrm{C}\right)$, the alkaline solution injected into the 
TABLE 3: Summary of sandpack flooding tests for Xia-8 and Binnan heavy oil.

\begin{tabular}{|c|c|c|c|c|c|c|c|}
\hline \multirow{2}{*}{ Run no. } & \multirow{2}{*}{ Heavy oil } & \multirow{2}{*}{ Viscosity (mPa.s) } & \multirow{2}{*}{ Permeability (mD) } & \multirow{2}{*}{ Initial oil saturation (\%) } & \multicolumn{3}{|c|}{ Recovery (\%) } \\
\hline & & & & & Water flooding & Alkali flooding & Total \\
\hline 1 & Xia-8 & 18235 & 1425 & 83.4 & 34.7 & 20.1 & 54.8 \\
\hline 2 & Xia-8 & 3950 & 1380 & 82.7 & 37.6 & 20.4 & 58.0 \\
\hline 3 & Xia-8 & 1083 & 1580 & 85.9 & 43.3 & 8.9 & 52.2 \\
\hline 4 & Binnan & 15030 & 1380 & 82.9 & 37.8 & 16.1 & 53.9 \\
\hline 5 & Binnan & 2500 & 1425 & 83.7 & 39 & 16.9 & 55.9 \\
\hline 6 & Binnan & 472 & 1380 & 87.1 & 42.9 & 3.9 & 46.8 \\
\hline
\end{tabular}

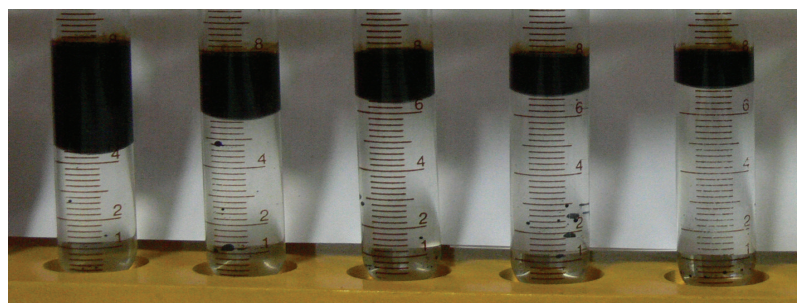

(a) $18235 \mathrm{mPa} \cdot \mathrm{s}$ at $30^{\circ} \mathrm{C}$

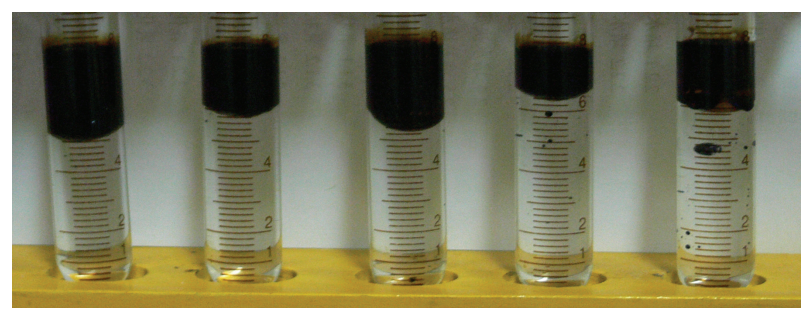

(b) $3950 \mathrm{mPa} \cdot \mathrm{s}$ at $50^{\circ} \mathrm{C}$

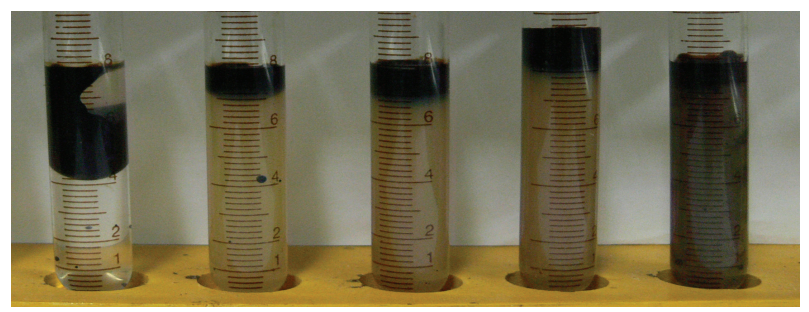

(c) $1083 \mathrm{mPa} \cdot \mathrm{s}$ at $70^{\circ} \mathrm{C}$

FIGURE 8: Pictures of the fluid produced during the displacement tests of Xia-8 heavy oil with different viscosities. (Effluents during alkali injection and the extended water flooding were collected in the tubes from left to right in turn. The pictures show their appearances at the end of flooding, without demulsification.)

sandpack mainly streams forward along the water channels and forms a muddy oil in water $(\mathrm{O} / \mathrm{W})$ emulsion, as shown in Figure 8(c). Consequently, heavy oil with a relative lowviscosity is unfavorable for alkaline flooding.

\subsection{Mechanism of Oil Viscosity on the Performance of Alkaline} Flooding. In conventional oil reservoirs, high-permeability and low oil viscosity are both favorable for development. However, the results of sandpack flooding tests indicate that this behavior is different for alkaline flooding in heavy oil reservoirs. Microscopic flooding tests were conducted to investigate the mechanism of this anomalous phenomenon, and the images intercepted from the flooding process are shown in Figure 9. It can be seen that there are a lot of water drops inside the oil phase existing in the models for both Chenzhuang and Zhuangxi heavy oils. These drops can plug the pore throats and improve the sweep efficiency for displacing phase. Compared to Chenzhuang heavy oil, the size of water drops formed in Zhuangxi heavy oil is obviously smaller, and numerous drops can exist in the same pore throat. These smaller water drops can effectively plug the small pores in the low-permeability cores, but this capacity decreases intensively in the high-permeability sandpacks. Therefore, good flooding performance could be achieved only in the low-permeability sandpacks. Figure 10 shows the pressure changes during the flooding process for the Zhuangxi heavy oil in the cores with different permeabilities. The displacement pressure increased significantly when the alkaline solution was injected into the low-permeability sandpacks; however, it changed little in the medium- and high-permeability sandpacks, which indicated that the water drops cannot plug the pores effectively.

In contrast, when the alkaline solution penetrated into the oil with a higher viscosity, that is, the Chenzhuang heavy oil shown in Figures 9(d), 9(e), and 9(f), the water drops were large, and even the throat could be occupied by only one drop. These water drops could plug the pores in both the lowand medium-permeability sandpacks and resulted in the high tertiary oil recoveries, as shown in Figure 4. In conclusion, the high-viscosity of heavy oil is favorable for the improvement of sweep efficiency in alkaline flooding.

The results of the sandpack flooding tests discussed in Section 3.1 indicated that the two oil samples could exhibit similar behaviors when these tests were conducted at different temperatures. However, the changing temperature may influence the dynamic water/oil IFT, which is very important for chemical flooding in conventional oil reservoirs. Therefore, dynamic IFT between the alkaline solutions and crude oils was measured. The results are shown in Figures 11 and 12, and little change is observed as the temperature varies. These results are inconsistent with the conclusions of Chiwetelu et al. [9] and Trujillo [10] as described in Section 1. Besides, it can be seen from Table 2 that the efficiency of alkaline flooding has little relation to the equilibrium IFT. So, we think many factors must be considered to design an alkaline flooding plan for heavy oil besides the IFT. 


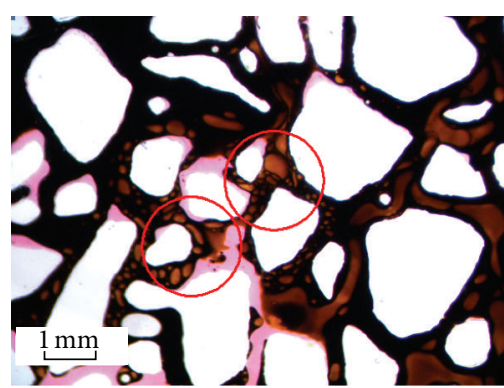

(a)

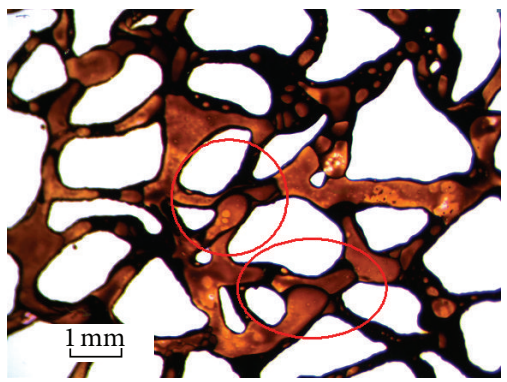

(d)

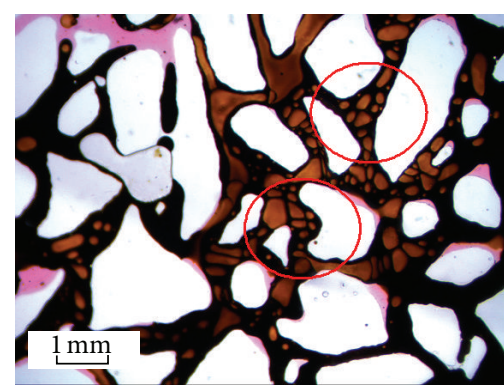

(b)

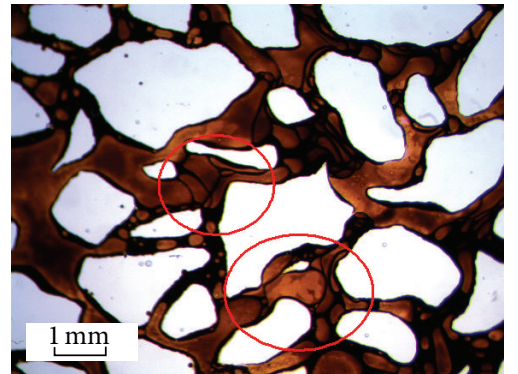

(e)

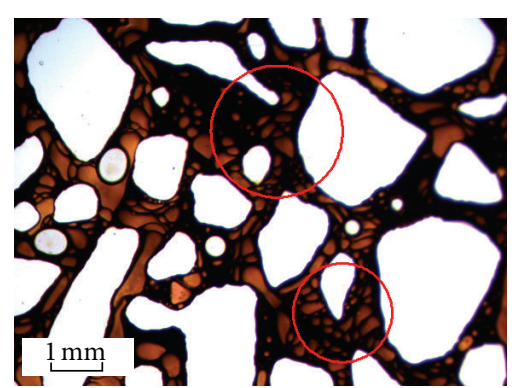

(c)

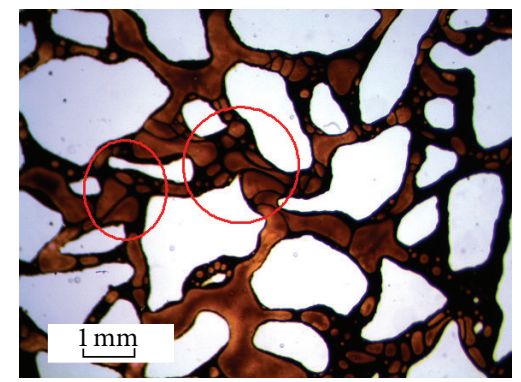

(f)

FIGURE 9: Microscopic images of alkaline flooding for different types of oil samples: (a), (b), and (c) Zhuangxi and (d), (e), and (f) Chenzhuang.

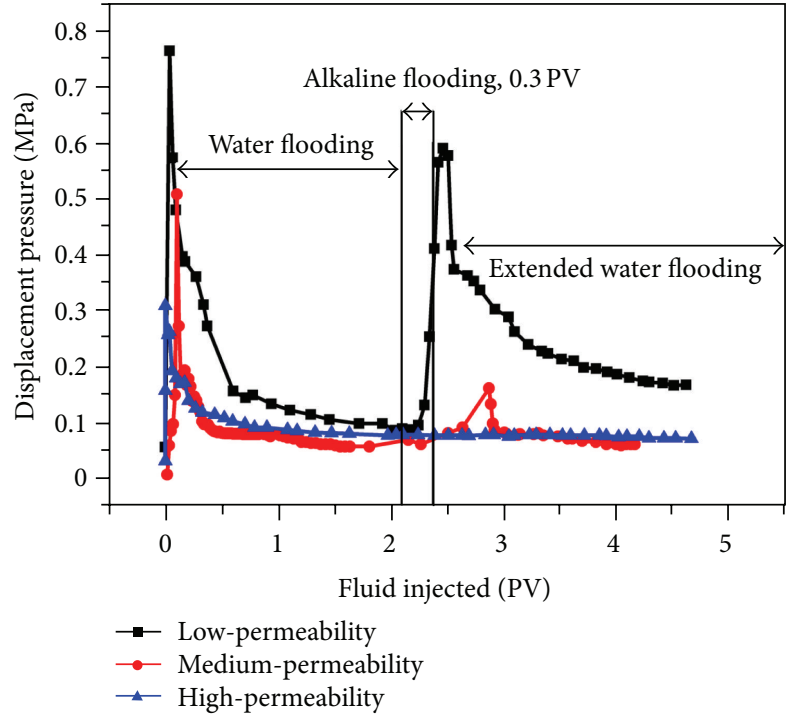

Figure 10: Pressure changes during alkaline flooding for Zhuangxi heavy oil (alkaline concentration $=0.5 \mathrm{wt} \%$ ).

As previously discussed, two stages occur in the waterdrop formation process. The first stage is the penetration of the alkaline solution into the heavy oil and the occurrence of water columns covered with oil film. This process is related to the fast reduction in the oil/water IFT, which is difficult to measure using drop-spinning method. The second stage is the formation of discontinuous water droplets from the breakup of the water columns, which is caused by the non-uniform enrichment of in situ surfactant [11]. High temperature accelerates the reaction and diffusion rate between alkaline solution and heavy oil, which reduces

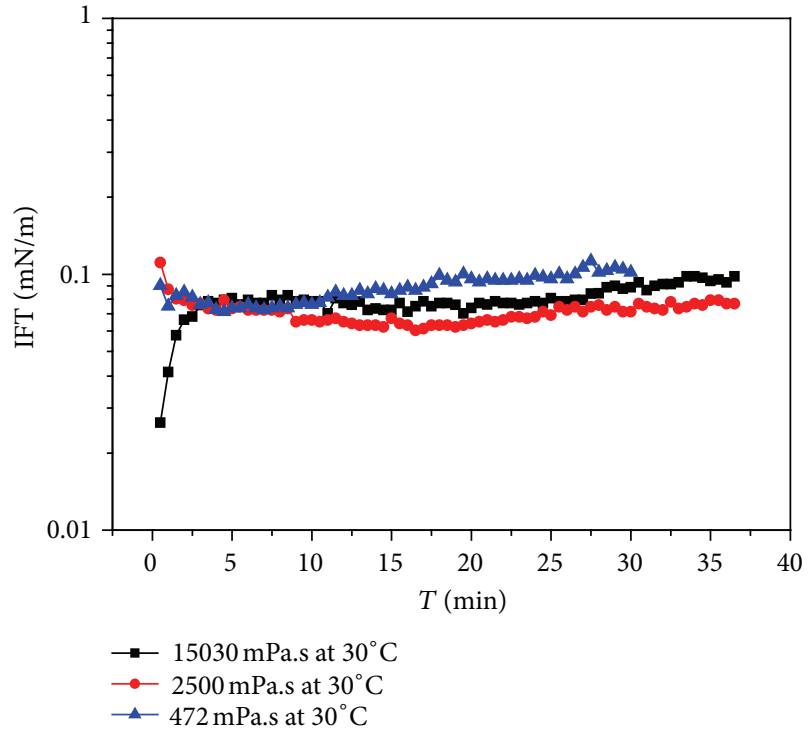

FIgURE 11: Dynamic IFT curves of Binnan heavy oil/ $/ 0.5 \% \mathrm{NaOH}+$ $0.5 \% \mathrm{NaCl}$.

the degree of non-uniform enrichment of in situ surfactant. The water columns then cannot be easily divided into small discontinuous water droplets. Therefore, the temperature militates the performance of alkaline flooding.

\section{Conclusions}

(1) The results of flooding tests indicated that a high tertiary oil recovery could be achieved only in the lowpermeability sandpacks for the low-viscosity heavy 


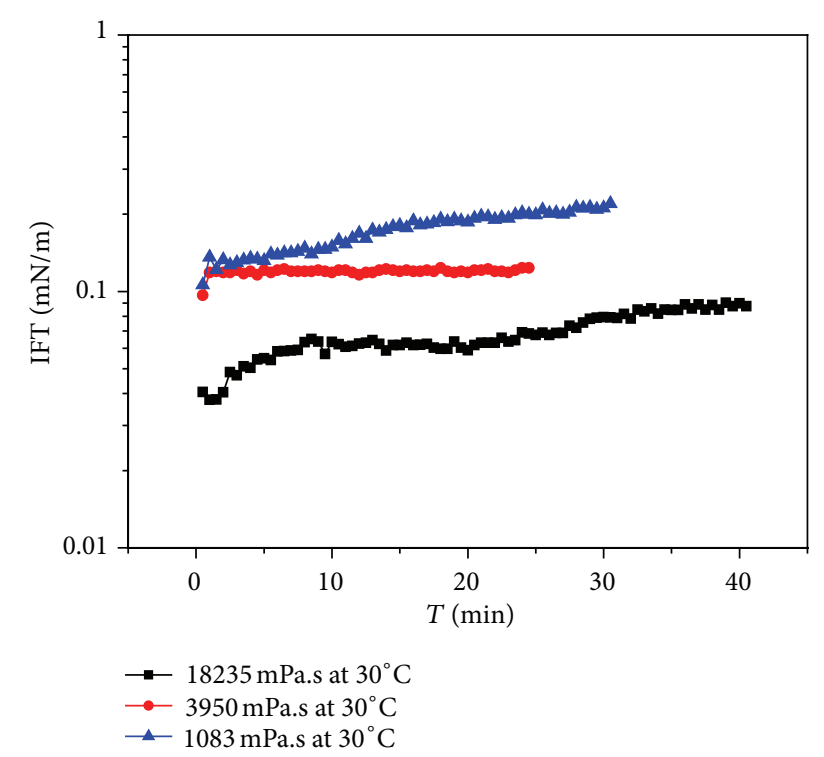

Figure 12: Dynamic IFT curves of Xia- 8 heavy oil/ $0.5 \% \mathrm{NaOH}+$ $0.5 \% \mathrm{NaCl}$.

oil; however, the high-viscosity heavy oil performed well in both the low- and medium-permeability sandpacks. In addition, the results of flooding tests for the same oil at different temperatures also indicated that the oil viscosity put a similar effect on alkaline flooding, and oil with a high-viscosity was favorable for alkaline flooding.

(2) Microscopic flooding tests were conducted to elucidate the influence of oil viscosity on the alkaline flooding. It indicated that the water drops produced during alkaline flooding for oils with different viscosities differed significantly in their sizes, which might influence the flow behaviors and therefore the sweep efficiencies of alkaline fluids.

\section{Acknowledgments}

Financial support from the National Natural Science Foundation of China (51104170), the National Natural Science Foundation of Shandong Province (ZR2011EEQ001), "Taishan Scholars" Construction Engineering (ts20070704), the Fok Ying Tung Education Foundation (114016), and the Research on the Displacement Mechanisms of Chemical Flooding for Water Flooding Heavy Oil from the State Key Laboratory of Heavy Oil Processing is gratefully acknowledged.

\section{References}

[1] C. E. Johnson Jr., "Status of caustic and emulsion methods," Journal of Petroleum Technology, vol. 28, pp. 85-92, 1976.

[2] H. Y. Jennings Jr., C. E. Johnson Jr., and C. D. McAuliffe, "Caustic waterflooding process for heavy oilscaustic waterflooding process for heavy oils," Journal of Petroleum Technology, vol. 26, pp. 1344-1352, 1974.
[3] C. E. Cooke Jr., R. E. Williams, and P. A. Kolodzie, "Oil recovery by alkaline waterflooding," Journal of Petroleum Technology, vol. 26, pp. 1365-1374, 1974.

[4] M. Dong, Q. Liu, and A. Li, "Micromodel study of the displacement mechanisms of enhanced heavy oil recovery by alkaline flooding," in Proceedings of the International Symposium of the Society of Core Analysts, pp. 2007-2047, Calgary; SCA, Alberta, Canada, September 2007.

[5] J. Bryan and A. Kantzas, "Enhanced heavy-oil recovery by alkali-surfactant flooding," in Proceedings of the SPE Annual Technical Conference and Exhibition (ATCE '07), pp. 3642-3654, Anaheim, Calif, USA, November 2007.

[6] B. Ding, G. Zhang, J. Ge, and X. Liu, "Research on mechanisms of alkaline flooding for heavy oil," Energy and Fuels, vol. 24, no. 12, pp. 6346-6352, 2010.

[7] M. Arhuoma, D. Yang, M. Dong, and R. Idem, "Numerical simulation of displacement mechanisms for enhancing heavy oil recovery during alkaline flooding," in Proceedings of the Canadian International Petroleum Conference (CIPC '09), pp. 2009-2053, Calgary; SPE, Alberta, Canada, June 2009.

[8] M. S. Almalik, A. M. Attia, and L. K. Jang, "Effects of alkaline flooding on the recovery of Safaniya crude oil of Saudi Arabia," Journal of Petroleum Science and Engineering, vol. 17, no. 3-4, pp. 367-372, 1997.

[9] C. I. Chiwetelu, G. H. Neale, V. Hornof, and A. E. George, "Recovery of a saskatchewan heavy oil using alkaline solution," Journal of Canadian Petroleum Technology, vol. 33, no. 4, pp. 3742, 1994.

[10] E. M. Trujillo, "Static and dynamic interfacial tensions between crude oils and caustic solutions," Society of Petroleum Engineers Journal, vol. 23, no. 4, pp. 645-656, 1983.

[11] H. Pei, G. Zhang, J. Ge, L. Jin, and X. Liu, "Analysis of microscopic displacement mechanisms of alkaline flooding for enhanced heavy-oil recovery," Energy and Fuels, vol. 25, no. 10, pp. 4423-4429, 2011. 

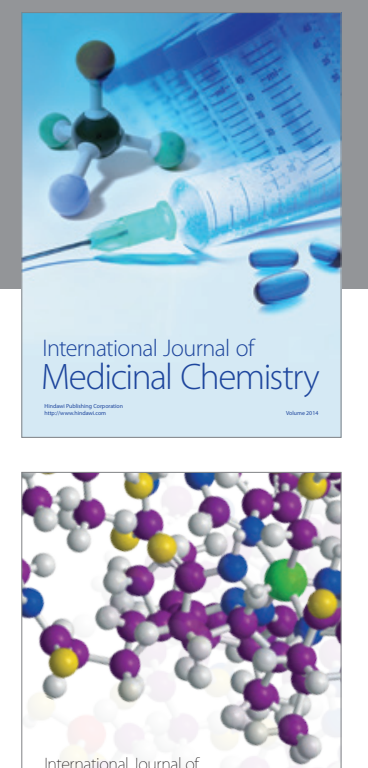

\section{Carbohydrate} Chemistry

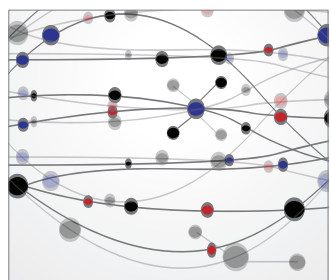

The Scientific World Journal
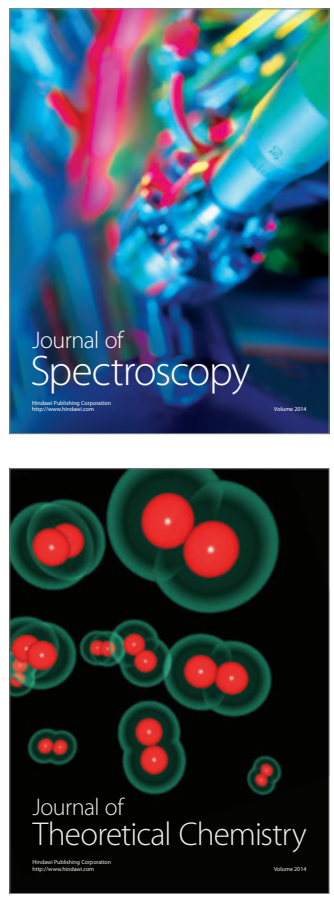
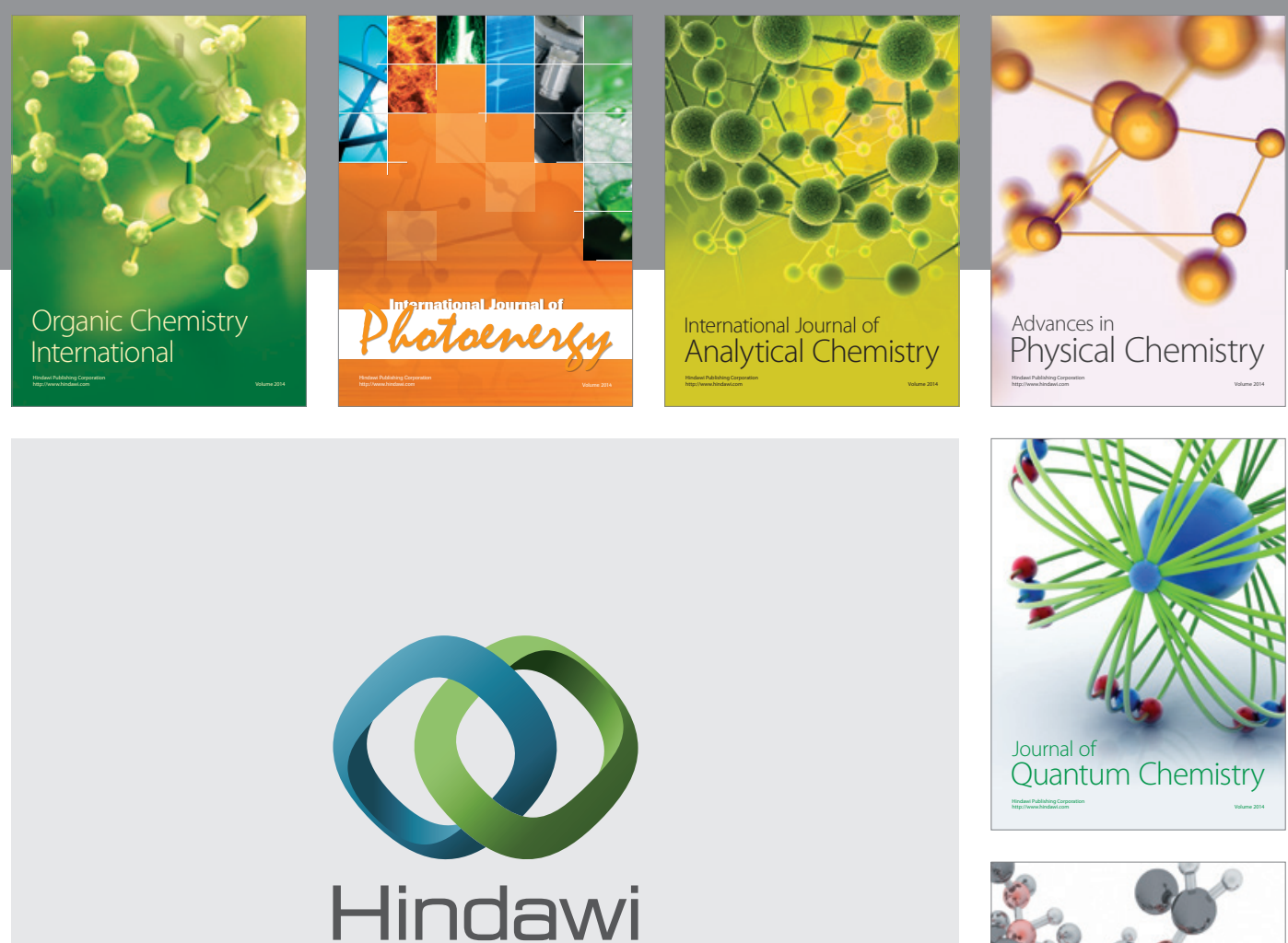

Submit your manuscripts at

http://www.hindawi.com

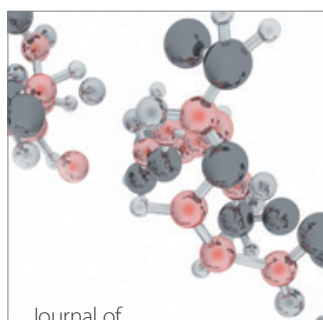

Analytical Methods

in Chemistry

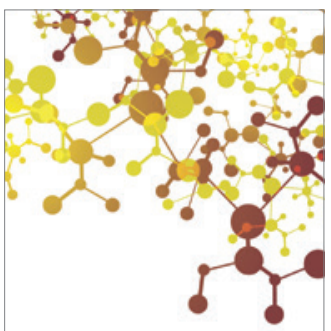

Journal of

Applied Chemistry

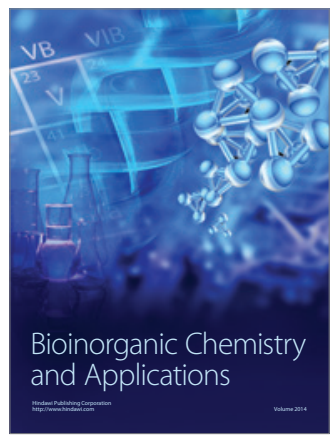

Inorganic Chemistry
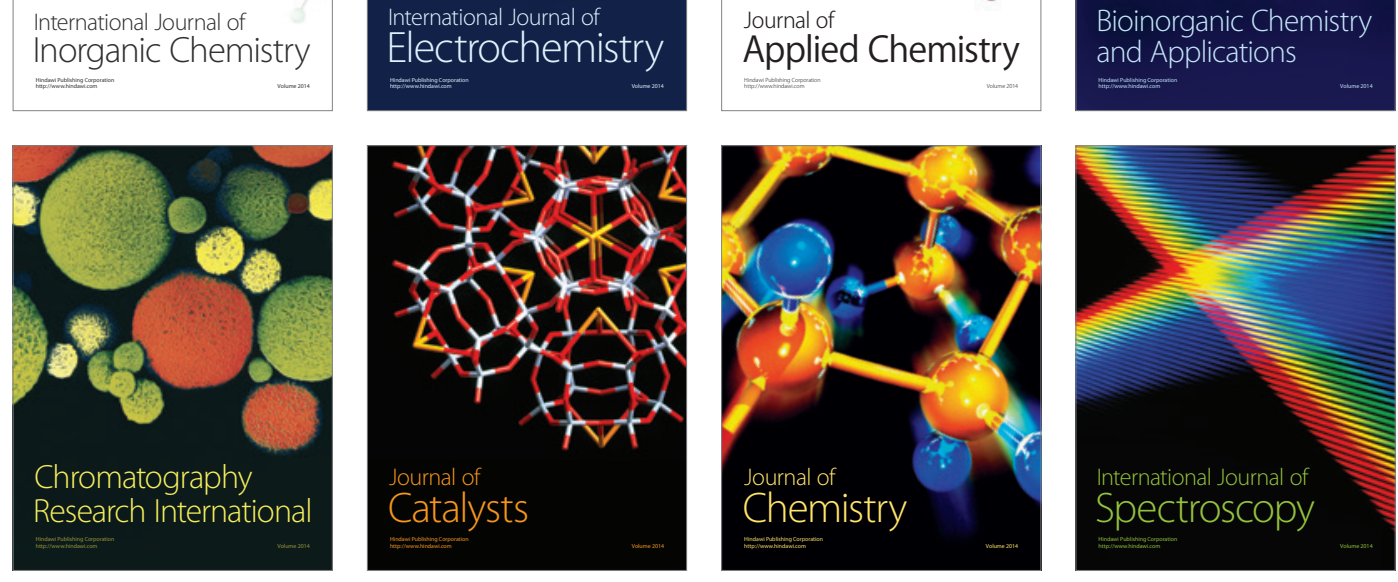